\title{
La ciudadanía española y los sefardíes. Razones históricas
}

The Spanish citizenship and the Sephardic Jews. Historical reasons

Dr. Adolfo Kuznitzky

fitok@arnet.com.ar

Buenos Aires

Argentina

\section{Resumen}

La reciente decisión del gobierno español de otorgar la ciudadanía española a los sefarditas dispersos por el mundo fue un acto de reparación histórica y en este trabajo procuramos rastrear en las razones de esa índole que la han fundamentado. Encontramos dos aspectos que seguramente se ha tenido en cuenta para su adopción. El primero lleva a valorar la presencia judaica en esa nación y para ello nada más indicado que el análisis de la muy conocida polémica que mantuvieron Claudio Sánchez Albornoz y Américo Castro y la historiografía en esa temática. El otro aspecto a considerar es la actitud de los españoles en los siglos XIX y XX hacia esos sefarditas, habida cuenta que para ese entonces, un hispanista opinó que España no solamente era una nación sin judíos sino que se había olvidado de ellos, y la reacción favorable que produjo su redescubrimiento, que se denominó Sefardofilia.

Palabras clave: Ciudadanía - Presencia judaica - El ser español - Sefardofilia Judeoconversos - Étnico. 


\begin{abstract}
Recent decision of the Spanish Government to grant Spanish citizenship to the Sephardic dispersed the world was an act of historical reparation and this work seek to trace on the reasons for such that have informed it. We find two aspects that surely has been taken into account for its adoption. The first leads to rating the Jewish presence in that nation and so nothing more appropriate than analysis of the well known controversy that kept Claudio Sánchez Albornoz and Américo Castro and historiography in this theme. The other aspect to consider is the attitude of the Spaniards in the 19th and 20th centuries to those Sephardim, taking into account that for that then, a hispanist opined that Spain was not only a nation free of Jews, but that he had forgotten them, and the favorable reaction that produced its rediscovery, which was called sefardofilia.
\end{abstract}

Keywords: Citizenship - Jewish presence - Seing Spanish - Sefardofilia - Conversos Ethnic.

La reciente noticia del otorgamiento de la ciudadanía española impone considerar algunos aspectos históricos de los judíos de España que entendemos deben haber influido para la adopción de tan importante decisión.

Las agruparemos principalmente en dos aspectos temporales: el de la valoración histórica de la presencia judía en España en el sentido de si esos judíos eran considerados españoles o eran gente extraña; y el de los sefarditas dispersos por el mundo como consecuencia de la expulsión de los judíos que hizo que España fuera una nación sin judíos y de la reacción que produjo su redescubrimiento. 
a) El primero de ellos fue tema de una ardorosa polémica entre Américo Castro y Claudio Sánchez Albornoz y que fue abordada por los mismos desde el punto vista historiográfico e identitario.

Quien vinculó esa presencia en la formación del ser español fue Castro basándose en que España surge por la interacción, rivalidades y cercanías entre las castas cristiana, musulmana y judía, o sea no solamente que los consideraba españoles sino que contribuyó configurar la nación. Esta interpretación histórica provocó la indignada respuesta de Sánchez Albornoz que dedicó nada menos que un libro para refutar esa posición, que entendía era exageradamente filosemita.

Remitirse a ese debate nos permitirá penetrar en el meollo de la cuestión planteada y arribar a algunas conclusiones.

¿Qué es lo que dijo Castro que tanta indignación provocó a Sánchez Albornoz? Fue esa opinión que mencionamos en relación a la fragua de la nación española y, además, se atrevió a identificar a los españoles con los sefarditas según lo siguiente términos:

(...) Y como hay fabulosos intereses invertidos en este asunto de la historia fabulosa, haría falta un Hércules para sacar de la cautividad a esta pobre historia... No se explica, en efecto, que en febrero de 1965, alguien respetable escriba: La hispanización profundísima y perdurable de los sefardíes, sin darse cuenta de la imposibilidad de separar lo español y lo sefardí. La expresión es tan ilógica como decir la españolización de los castellanos (Castro, 1971, p. 17). 
Es que para Castro "La historia del resto de Europa puede entenderse sin necesidad de situar a los judíos en un primer término; la de España, no"1. Sánchez Albornoz esencialmente desarrolla su pensamiento de la siguiente manera:

Pocas páginas de la historia de España han suscitado tan formidable marejada de pasiones como las que refieren los contactos de españoles y judíos. Fueron tan agrios que todavía siguen batiendo los acantilados de la verdad histórica olas de apasionados comentarios. Ningún español culto siente hoy antipatía alguna hacia el pueblo hebreo, pero aún están vivas las sañas hebraicas contra España... Y suscribo sin vacilaciones cuantos elogios puedan hacerse sobre el ímpetu de pensamiento, la capacidad razonadora, la fina espiritualidad de la minoría culta de lo hebreos peninsulares. Pero cualquiera que sea la admiración y simpatía que me inspiren las empresas espirituales del pueblo judeo-español, me es preciso dejarlas aquí de lado, porque no contribuyeron a la forja de lo hispano. La contribución de los judíos españoles a la acuñación de lo hispánico fue muy otra y siempre de carácter negativo, quiero decir que no trasmitió calidades sino que provocó reacciones. Nada de lo esencial de la contextura psíquica del pueblo hebreo dejó huellas entre los españoles. Más aún, una tajante oposición enfrenta lo hebraico y lo hispano...Es más fácil unir el agua con el fuego que hallar vínculos de parentesco entre lo hispánico y lo hebraico (Sánchez Albornoz, 1973, p. 163-4-76).

Frente a estos planteamientos el hispanista Joseph Pérez se pronuncia adhiriendo a la opinión de Castro expresando que:

\footnotetext{
${ }^{1}$ Los judíos sefarditas: quiénes fueron y quiénes son. Publicado el 9 de septiembre 2014, de http://www.abc.es/archivo/20140216/abci-judios-sefarditas-espana-201402141746.html
} 
Es muy acertada la aclaración de Luis García Iglesias: Nos parece, pues, inadmisible la observación de Sánchez Albornoz en el sentido de que los judíos constituían gentes extrañas a la vida peninsular. Esa extrañeza no iba más allá de lo que de extraño pudieran tener sus creencias y cuanto con ellas se relacionara (Pérez J, 2005, p. 20).

Quienes se oponen a Sánchez Albornoz lo consideran un esencialista porque creía en una España eterna y ahistórica, y para algunos sus opiniones están muy cerca del antisemitismo. En este sentido Netanyahu (2005, p. 126) sostiene que las afirmaciones de Sánchez Albornoz tienen claramente un propósito apologético a favor de los españoles, porque entendía que lo que produjo la ruina de los judíos en España se debió a su propia conducta e ideas de ellos y que el pueblo español no merecía las críticas con las cuales se las estigmatizó y que constituye una de las versiones de la leyenda negra española. Es por elloseñala- que el propósito de Sánchez Albornoz fue presentar la historia hispano-judaica de forma que permitiera un juicio moral favorable al pueblo español. Ese juicio -según Netanyahu- lo elabora Sánchez Albornoz como lo hacen los españoles que tienen el hábito de investigar su alma nacional colectiva (delimitar las esencias, como señaló García Cárcel (1998, p. 241).

Agrega, además, que quienes se dedicaron a esa tarea quieren "saber qué es lo que constituye a un español como tal español y en qué se diferencia de los miembros de otras naciones" y considera que ello es considerado, por Netanyahu como un error porque cualquier intento de definir el carácter o las notas morales de toda una nación le parece abocado al fracaso desde el principio y puede inspirar especulaciones fantasiosas.

Contreras también descree de las identidades colectivas, porque considera que esa concepción es por naturaleza arbitraria, al ser arbitraria la elección de los rasgos con 
respecto a un concepto técnicamente definible, a priori, como corresponde a una entidad natural.

Es por esa misma razón que para Netanyahu es imposible hablar de esos temas con rigor, ya que cualquier rasgo que se pueda detectar en algunos miembros de su grupo está compensado por rasgos contrarios del mismo grupo y por muy generalizadas que estén ciertas actitudes, no son permanentes. Para este autor, Sánchez Albornoz ve al pueblo judío como un fenómeno monolítico, desde los días de Moisés hasta su propio tiempo y se cree capaz de definir la esencia de los judíos como se definen las características peculiares de las especies vegetales y animales.

En realidad los juicios de Sánchez Alboroz sobre el judaísmo español oscilan entre una negatividad cerril a otros que son positivos. Un ejemplo de ese equilibro que procura, surge cuando cuestiona cuantitativamente el factor demográfico que algunos sostienen, aunque admite la potencia mental del pueblo hebreo hispano señalando que:

(...) No me merecen crédito los cálculos muy discutibles, y siempre contradictorios, con los que se ha intentado fijar las cifras de la población hispano judía. Creo que fue más reducida de lo que se pretende. Pero cualquier que fuera su número, siempre habría sido grande la proporción de los judíos doctores en el conjunto de nuestra grey mosaica, a juzgar por las noticias que poseemos sobre sus hombres de letras y ciencias. Esa desproporción atestigua la potencia mental del pueblo hispano hebreo y su gusto por dedicarse a las tareas del espíritu... (Sánchez Albornoz, 1973, p. 260).

No obstante tampoco subestima esa dimensión demográfica, que tiene especial cuidado en no cuantificar, y cuya importancia combina con otros factores sociales y políticos: 
(...) La reconquista y la repoblación fueron factores de enorme importancia en el aumento y en la influencia social y política de la minoría judaica en los reinos cristianos...no habrían alcanzado el número y relieve que lograron en León y Castilla y también los otros estados peninsulares... entraron en Castilla millares y millares... (Sánchez Albornoz, 1973, p. 177 y 178).

Luego, en otra situación de parecidos alcances equilibrantes, refiere, cuando alude a que durante la Reconquista la necesidad de repoblar era tan intensa que hizo que por esa razón se hubiese convocado al diablo en persona. Podría pensarse, habida cuenta el interés demostrado hacia ellos, que esa urgencia hacía que se dejara de lado alguna consideración negativa de los judíos. Sin embargo, cuando habla de ellos, señala que: “(...) Con cuánto más placer se aceptaría como colonizadores a los laboriosos judíos... iy que por ello los reyes cristianos les abrieron las fronteras de sus reinos gozosos de ver incrementar así la población de sus ciudades!”. Sigue -luego- con sus alabanzas, utilizando expresiones como “industriosas masas hebraicas” (Sánchez Albornoz, 1973, p. 177).

Estas expresiones, como las que veremos, están inscriptas en su estilo que metafóricamente podríamos llamar contable, porque entiende que en el balance de créditos y débitos entre ellos y los españoles las cuentas quedaron saldadas. Resulta evidente que este historiador español trata de emitir juicios equlibrados, repartiendo -como vimos- elogios y deméritos, según cree que correspondan, pero para ser sinceros, y sin que esto sea una falta de respeto, creemos advertir que marca diferencias tan tajantes entre españoles y judíos que si bien no podemos pensar provengan de una mentalidad antisemita, dadas sus convicciones políticas que lo obligaron a exiliarse por ser republicano, su imparcialidad -nos parece- queda un poco afectada, quizá no por un rencor antijudaíco, pero sí por ese temperamento tan propio de los hispánicos cuando discuten; y con Castro ¡vaya si discutieron!

En sus juicios sobre las sañas hebreas contra España no encuentra explicable el drama y la injusticia de la expulsión que hablan por sí solas. Hay historiadores que desde una 
concepción tradicionalista justifican, y otros defienden, su necesidad, pero ni aún a los más cerriles de ellos se le ocurrió pensar que un hecho de esa naturaleza no produciría traumas. Por ello, los odios y rencores hacia quien los agravió de tal manera tienen explicación histórica. Estaría fuera de toda lógica que los hechos no hubieran ocurrido de esa manera: a una acción injusta, o que se crea injusta por el destinatario de la misma, siempre sigue una reacción que también puede ser injusta, como es la saña, pero comprensible en el plano de la psicología humana.

Tratándose, como se trata, de historia judaica, no podía faltar el remanido tema de la usura, y esto nos recuerda el pensamiento de la escritora Dujovne Ortiz cuando en un artículo sobre la esclavitud señala que pocos pueblos han quedado fuera de la responsabilidad de haberla explotado, sobre todo España, y cuando se refiere a los judíos nos cuenta que están eximidos de ella, pero no por una cuestión de limpieza, sino porque no se sabe qué hubieran hecho si hubieran tenido la oportunidad. No hay, explica, pueblos más honestos y más limpios que otros, por lo menos es lo que enseña la historia, y todo es cuestión de oportunidad (Dujovne Ortiz, 2005). Si bien fue un hecho histórico de incontrastable realidad que algunos judíos se dedicaran al préstamo de dinero, hubiera correspondido que aclarara que ese rol casi fue impuesto por la sociedad y la Iglesia. Aún siendo así, se lo presenta como casi siempre ocurre con los judíos, en forma exagerada y generalizada, y además, sin hacer mención que los banqueros que sangraron a España no eran hebreos. Obsérvese que cuando habla de los estímulos hacia los judíos para que repoblasen los territorios desérticos que iban quedando se los eximió de la orden conciliar de usar señales identificatorias, está reconociendo las restricciones a que estaban sometidos. Además, Lacave (Lacave, 1992 p. 53) señala que los banqueros y recaudadores judíos eran muy pocos, y que estos eran seres humanos, nada más ni nada menos, y cabe la posibilidad de que no todos los prestamistas hayan sido usureros ni que todos los préstamos hayan tenido ese carácter (Lacave, p. 167 ). Que hay actividades que son más antipáticas que otras, puede explicar el odio y la envidia del pueblo, pero ello no merece un reproche histórico por parte de un historiador profesional. Así como Sánchez Albornoz sigue a Renán para 
distinguir a españoles de judíos, debió de haber tomado en cuenta su opinión al respecto, que fue la siguiente: "La Edad Media le reprochó al israelita la misma profesión a la cual lo condenó" (Avruj, 2005).

Suárez, a su vez, dirige una crítica muy severa a ese tipo de juicio histórico, al señalar que "Nada tan fácil como generalizar; en España donde sólo una minoría de judíos se dedicaba a operaciones de crédito, la práctica de la usura fue atribuida a todos...”, y explica además que “(...) Resultaba muy difícil distinguir entre créditos legítimos y préstamos usuarios...” (Suárez, 2003, p. 349).

En este mismo sentido de provocar odios populares, también señala que la existencia de ciertas oligarquías judaicas, que vivían como los nobles cristianos, copiando sus vicios y frecuentemente poco consecuentes con su fe, “eran los ejemplos que los cristianos tenían ante sus ojos y, generalizando, extendían sus defectos y afán de riquezas a todos los judíos...”.

En este caso, Suárez también aclara, dando a entender que no comparte la opinión reduccionista, que atribuye a una comunidad los defectos de unos pocos de sus miembros, que en el siglo XIII los judíos exhibían ciertas virtudes en España: “(...) su intensa vida de piedad, o la solidaridad interna con que se sostenían rabinos, lectores, estudiantes, viudas, pobres y huérfanos, eran absolutamente desconocidas...” (Suárez, 2003, p. 356).

Tampoco se puede hablar de este tema y no mencionar que muchas veces a los cristianos les convenía hacer que desaparecieran las documentaciones que instrumentaban las deudas, y para ello nada mejor que demonizar a los acreedores. Además, y en este mismo sentido, Suárez cita una situación que los concejos preferían acudir a banqueros judíos antes que a sus bienes propios, dado que de acuerdo una legislación especial (Madrigal), éstos no podrían encontrar testigos cristianos, que era el único medio de prueba admitido para 
demostrar sus derechos. Esto, en resumidas cuentas, significaba que se tomaba el dinero con absoluta mala fe (Suárez, 2002).

En un estudio sobre la imagen del judío en la España medieval, Cantera Montenegro, al analizar diversas obras de apologética antijudía, puntualiza los argumentos de carácter económico que se utilizan expresando que la acusación de usura lanzada contra los judíos es un tema recurrente, y entiende que al respecto abundaban peligrosamente las exageraciones y los bulos que corrían acerca de las riquezas desmedidas, con lo que se convertía en rasgo universal algo que sería representativo de un pequeño sector de la misma (Cantera Montenegro, 1998, p. 31).

Observemos las diferencias de enfoque tan notorias que muestra Suárez, de quien queremos remarcar que publica en revistas católicas. Además, su seriedad está respaldada por ser miembro de la Academia de la Historia de Madrid, y su opinión contrasta contra la de Sánchez Albornoz, que nos habla de la devoción de los hebreos hacia los bienes materiales (Sánchez Albornoz, p. 187).

En este último, entre otras diferencias que dice encontrar en judíos y españoles, se advierte un afán por profundizarlas en lo religioso. Las remarca enfáticamente mostrando la oposición existente entre la redención judía, de carácter colectivo, de la cristiana, de carácter individual, sosteniendo:

Es difícil -dice- hallar nada más opuesto a lo auténtico español que estos rasgos esenciales de lo hispano judío. Frente al triunfo de lo social en el pensamiento religioso hispano-hebraico y en la vida misma de las comunidades hebreas se alza el hiperindividualismo hispano. El mesianismo hizo vivir a los judíos peninsulares cara al 
mañana en una prolongada e ininterrumpida espera de un futuro luminoso y triunfador.

El español miró con mucha frecuencia hacia el ayer (Sánchez Albornoz, p.176).

Sánchez Albornoz entiende también que esta diversidad se da porque al triunfar en la religión hebraica lo colectivo sobre lo individual, el vínculo más esencial es de Israel con el Altísimo, más que la relación del hombre con Dios, y en el ápice de la jerarquía de los señores del mundo no está el hombre, sino el hombre israelí, por pertenecer al pueblo que ha recibido la ley (Sánchez Albornoz; p. 104). Está aludiendo al pueblo elegido, argumento éste que ha servido en mucho al antisemitismo. Valerse de una interpretación literal, en textos que deben ser interpretados en contexto, no es lo correcto, y así como hay diversas interpretaciones de muchas partes de la Biblia, una de ellas, que nos parece la más apropiada, es de que la elección como pueblo no fue un privilegio, sino una carga. Además, y como señala Netanyahu (Kuznitzky, 2006, p. 138) tampoco esa elección divina implica superioridad, sino simplemente una elección de Dios, y solamente él sabe las razones. En ese sentido también nos permitimos reproducir un texto de Levinas porque penetra magistralmente la cuestión:

(...) es para toda la humanidad que llegó el judaísmo. Tenemos la reputación de creernos el pueblo elegido y esta reputación provoca mucho daño a ese universalismo. La idea de un pueblo elegido no debe ser considerada como un orgullo. No es conciencia de derechos excepcionales, sino de deberes excepcionales. Es el atributo de la conciencia moral misma. Conciencia que se sabe en el centro del mundo y para ella el mundo no es homogéneo... La elección es un plus de obligaciones por el cual se enuncia el "yo" de la conciencia moral..." (Levinas, 2004, p. 221). 
No olvidemos que se trata del mismo Dios que tienen los cristianos. Los protestantes comprendieron y aceptaron esa elección divina. Por otra parte, Dujovne (1949) nos dice que la mayoría de las plegarias del judío se refieren a la humanidad entera y no a un pueblo en especial. Si bien en esto bien sigue a un hebraísta como Millas Villacrosa, se advierte su propósito de mostrar al judío como una persona dominada por los intereses materiales y, en este caso, mezclando lo religioso con lo racial, al citar la concepción de Renán, (Sánchez Albornoz; p. 167 y 176), cuando, por otra parte, reconoce, luego, su gusto por dedicarse a las tareas del espíritu o la fina espiritualidad de la minoría culta de los hebreos peninsulares (Sánchez Albornoz; p. 54 ) y el movimiento cabalístico. En el otro extremo, por supuesto, muestra al cristianismo, y con ello al español, como inspirado por lo espiritual.

Esto último se vincula, también, con el tema de la inmortalidad, dado que -apunta- el pensamiento hebreo no ha puesto acento especial en el mismo. Cuando cita las angustias de Job, omite decir que ese capítulo es tan importante que Dujovne lo incluye como fundamento, por el reclamo de justicia, de la existencia de una Filosofía Judía y la carencia -expone- de una vida inmortal que pueda realizarla (Dujovne, 1949, p. 33). Además, omite señalar que, según Fonti, en el período rabínico posterior a las Escrituras se desarrolla la doctrina farisaica de la resurrección de los muertos, en un mundo futuro (Fonti, 2005, p.72). Aún para el supuesto de admitir rasgos diferenciales, derivados de una visión menos trascendente del ser humano, y más preocupado por lo terrenal, lo que no significa -como se verá- interés por lo material, hay que tener presente, además, que el judaísmo es la base de la religión que defiende (Sánchez Albornoz; p.164), salvo que adhiera al marcionismo, que intentó desvincular totalmente ambas religiones, desconociendo el origen del cristianismo. Esto lo señala la erudita obra de Karen Armstrong, cuando nos dice que "El cristianismo hizo de una persona humana el centro de la vida religiosa de una forma única en la historia de la religión: llevó a su extremo el personalismo intrínseco del judaísmo" (1995, p.250.) 
La declaración papal de "nuestros hermanos mayores" es el reconocimiento máximo de que no puede existir ese quiebre y que el cristianismo reconoce todo lo veterotestamentario. Suárez nos enseña que a comienzos del siglo IV la Iglesia tuvo que definirse a sí misma y buscó el afianzamiento de todo aquello que la separaba del judaísmo, condenando a éste como una consecuencia de su desobediencia a los mandatos de Dios, y que consistía en no aceptar a Jesús, lo que hizo olvidar la doctrina paulina acerca del olivo y del acebuche, con lo que trata de significar que en los comienzos las diferencias doctrinarias no fueran esenciales, como plantea Sánchez Albornoz, y que lo posterior obedeció más que a lo doctrinario a una necesidad de diferenciación.

Rosenzweig vincula a ambas religiones afirmando que el judaísmo es la "llama" o la "vida eterna" y que el cristianismo, a su vez, propaga por el mundo los "rayos" que brotan de la llama (Dujovne, 1949, p. 225). Pensamos que tal como plantea esa diferenciación, obedece a la necesidad de refutar a Castro cuando fundamenta la contextura semítica de los españoles en el exclusivismo religioso de los judíos, dado que el volumen de su fe ultraterrena se parece más a formas de religiosidad judías o islámicas que europeooccidentales (Castro, 1971, p 12).

Nos parece excesivo pretender marcar las desemejanzas a partir de la religión -que como vimos no son tan esenciales-, sobre todo porque las entiende tan profundas como para impedir que se comparta una nacionalidad. A nadie se le ocurriría negar la categoría nacional de inglés o alemán a una persona nacida en los países correspondientes, por el hecho de pertenecer al catolicismo, u otra religión minoritaria.

Cuando, para seguir marcando el diverso perfil entre ambos pueblos, nos habla del pensamiento judaico, tiene -según se vio- inquietudes terrenales, tenemos que señalar que el pensamiento católico también las tiene. Surgen de la política social de la Iglesia, como la encíclica Rerum Novarum, lo que se podría decir que es por la influencia judía. Armstrong (1995) señala, al igual que Suarez, que los judíos -según la Biblia- ya contaban con un 
sistema de seguridad social y preocupación por la gente pobre. Es cierto que el judaísmo presenta esas características, al punto que algunos dicen que el marxismo (mesianismo secular) es una nota al pie de página del judaísmo, pero de ellas no está lejos el cristianismo en la actualidad.

Cuando hace el distingo entre lo terrenal y la espiritualidad, está aludiendo indirectamente a que los judíos son racionalistas, y está dejando de lado el movimiento cabalístico, que en otro lugar del libro reconoce, y la fuerte oposición que hubo al pensamiento racionalista de Maimónides. Además, y si de racionalismo se trata, también se contradice porque defiende esta concepción desde el punto de vista religioso, cuando critica a Lutero por sostener que había que dar muerte a la razón.

Curiosamente, y a pesar del empeño puesto en esas diferenciaciones, hay otro aspecto en el que los españoles sí se diferenciaban, pero Sánchez Albornoz sostiene que no fue así. Se trata de los oficios o menestrales, como les llama, y esta opinión más que todo está enmarcada en la discusión con Castro, dado que éste sostuvo que los españoles rechazaron, para no ser tildados de judíos, cualquier actividad mental o práctica que pudiera parecer propia de hispano-hebreos ${ }^{2}$, lo que habría llevado a España a una parálisis por la no participación en las tareas científicas y económicas de los otros pueblos europeos. Para aquél no es correcta la imagen de una minoría judaica realizando, sin competencia, tareas desdeñadas por las masas españolas, incapaces de interesarse sino por el integralismo y señorío de su persona, ya que existieron abundantes artesanos cristianos. Entiende que hasta la paralización de la reconquista, los cristianos pudieron vivir soñando en alcanzar la riqueza a punta de lanza, pero después no. En realidad, es probable que en la controversia no se tomen en cuenta los períodos a los cuales se refieren las afirmaciones que son su objeto.

\footnotetext{
${ }^{2}$ Mayagoitía y Hagelstein, Alejandro: "De Real a Nacional. El ilustre Colegio de Abogados de México". Creemos que lo que sostiene Castro tiene fundamento, porque ese Colegio de Abogados entre las preguntas que formulaban en las informaciones genealógicas, para verificar si los interesado en ejercer la decorosa profesión de abogados figuraba aquélla relacionada con oficios viles o mecánicos.
} 
Pensamos que en la realidad las diferencias no fueron tan notorias, si pensamos con Castro que los judíos estaban arraigados culturalmente en Castilla y en León (Castro, 1971, p. 9), que solían ser padrinos y compartían actividades sociales y que físicamente no se distinguían mayormente, según la opinión de Domínguez Ortiz, de lo que Sánchez Albornoz no parece muy convencido cuando, por ejemplo, pone en duda el origen judaico de Vives por su aspecto.

Por otra parte, cuando habla de cuenta saldadas, y de las sañas de los hebreos contra los españoles, sostiene que los españoles no fueron más crueles que los otros pueblos de Europa, creemos que omite algo tan importante como la limpieza de sangre, limitándose, según Márquez Villanueva en el prólogo de la obra citada, a reconocer en la misma un "nudo trágico", de la misma manera que Menéndez Pelayo la trata de "antipático asunto" (Domínguez Ortiz, 1991, p. 16)

Esto lo remarca Domínguez Ortiz, subrayando con algo más de énfasis, siguiendo con la jerga contable, ese débito, al señalar que era algo desconocido en el resto de Europa. Una cuenta tan severamente gravosa como resulta ésa, desequilibra los saldos.

En efecto, en los debates por la implantación de los Estatutos de Limpieza de Sangre, quienes se oponían alegaban que en otras naciones tan severas exigencias biológicas no se daban (Domínguez Ortiz; p. 236), lo cual, además de revelar la importancia histórica de esa medida como de su tenebrosa motivación, demuestra que la nación española trascendió todo lo conocido hasta esa época en materia de antijudaísmo.

Y donde parecería surgir nítida su animadversión a los judíos, es con su opinión sobre que la Expulsión por el bien de España debió haberse adoptado con anterioridad expresando lo siguiente: 
Creo por todo ello -y no he de callar mi opinión aún a riesgo de escandalizar a muchos y de incurrir en la excomunión mayor de otros- que la expulsión de los judíos hispanos fue tardía. Realizada un siglo y medio antes de 1492, habría cambiado la psiquis de los españoles y la faz económica de España. El giro decisivo de la historia de Inglaterra coincidió con la expulsión de los hebreos: forzó a los ingleses a reemplazarlos en sus empresas económicas y, al liberarse de su terrible ventosa, favoreció el libre y creciente despliegue de su riqueza industrial y mercantil (Sánchez Albornoz, p. 228).

Si bien hay cierta banalidad en el tratamiento de ese juicio contrafáctico, sobre todo porque en Inglaterra la presencia judía fue poco relevante, se puede decir no hubo una carga antisemita en el mismo -pese a que prevé una reacción para que se lo considere de esa manera por -dice- "escandalizar" -, sino que, razona, que de no haber existido los judíos, los españoles habrían tenido que hacer un aprendizaje forzoso y desarrollar habilidades financieras, así como el hecho forzó a los ingleses a reemplazarlos en sus empresas económicas. Se trataría de una finalidad utilitaria y no ideológica. No obstante al calificar a la presencia judía como una "terrible ventosa" nos está remitiendo a la misma imputación de la usura judía por lo que entendemos que los mismos argumentos que utilizamos para refutarla sirven para desvirtuar la cuestión tratada. Es por ello que reprocha a dos reyes, porque, sin culpa de los judíos, los favorecieron desaforadamente, al punto de tener el dominio de la hacienda real, lo que causó daño a Castilla y a los mismos hebreos (Sánchez Albornoz, p. 227).

Parecería -según su razonamiento- que las mismas tareas efectuadas por no judíos se "beatificaran". Además, resulta contradictorio lo que señala: aquello de que no hubiera sido posible la expulsión -tal como él lo hubiera deseado-, porque todavía no estaban unidas Aragón y Castilla, lo que habría posibilitado el peligro de que los expulsados de uno de los 
dos reinos huyeran al otro y acrecentaran su población y potencial tributario. Si fue deseable su expulsión, con mayor razón hubiera sido su alejamiento voluntario. Y si el ir a otro reino significaba una mejora del mismo, ¿para qué se los expulsaría?

Cuando se refiere concretamente a la expulsión, desliza una opinión que además de original nos da una explicación -de ésas que a él no le agradan- en clave judaica, porque releva de esa responsabilidad a Fernando el Católico, dado que no la hubiera podido adoptar motu propio, por ser nieto de judíos por el lado de su madre, Doña Juana de Enríquez, amén de su relación con ellos (Sánchez Albornoz, p. 259).

Además, esta cuestión está directamente relacionada con la de la "decadencia de España", que consumió ríos de tinta, por lo que este recurrente tema de la cuestión judía vuelve a estar presente en forma ambivalente, entre autores como Sánchez Albornoz, o quienes como Vives -desde el otro extremo- encuentran en la expulsión a una de las causas de esa evidente declinación. Lo concreto es que los judíos constituyeron en España lo que sería una especie de burguesía o clase media y su ausencia o desaparición con toda lógica no puede, por esa razón, haber resultado indiferente. En relación a la opinión de Vincens Vives, este autor concretamente sostiene:

La expulsión eliminó de la vida social a los únicos grupos que habría podido desarrollar el primer movimiento del capitalismo; minó las bases de la prosperidad de numerosas ciudades y movilizó una enorme cantidad de riquezas, cuya parte sirvió para financiar la política exterior de los Reyes Católicos, dispersándose en las manos de la aristocracia (Vives, 1978, p. 12).

Ahora bien, donde a lo mejor no escandaliza, pero sí está cerca de ello, es cuando para ilustrar acerca de la diversidad entre españoles y hebreos, apela -según vimos- a la que 
surge entre arios y semitas, por su distinta pertenencia. Usa esas categorías que según ya hemos visto también fueron utilizadas para distinguir las concepciones religiosas. No nos atrevemos a calificar -en el sentido que le dimos al tratar la cuestión el capítulo correspondiente- como racista a esa opinión, sobre todo porque no tiene una postura poligenista definida, pero tampoco la tiene como monogenista, porque entiende que la ciencia no nos ha resuelto el problema del origen del hombre.

Además, e ingresando a un terreno étnico o racial, estas diferencias se advierten más en los pueblos nórdicos que en los mediterráneos, salvo de su nostalgia por lo gótico, que trasciende la realidad, como lo señalara Caro Baroja. Si un español, que es un severo franquista, como Giménez Caballero, identifica por su morenidad a esa nacionalidad ${ }^{3}$, lo que lo contradice en su afán goticista. De todas maneras, tenemos que pensar que el juicio no es peyorativo, habida cuenta el reconocimiento de importantes méritos en otra actitud que pareciera querer neutralizar la formación de una idea negativa acerca de su persona. No podría ser antisemita ni racista quien escribe estas palabras:

(...) Porque soy de los que creen que, en España, del rey hacia abajo ninguno puede estar seguro de no contar con algún judío entre sus antepasados, y tanto menos cuanto más cerca se encuentre de cualquiera de la altas jerarquías sociales... “(...) No he de regatear tampoco a los judíos hispanos la importancia de su papel de intermediarios entre las culturas de Oriente y de Occidente en la Península... Su superioridad cultural sobre las otras comunidades hebraicas europeas medievales es indiscutible, y lo es su proyección en la cultural moderna a través de nietos de judíos españoles como Montaigne y

\footnotetext{
${ }^{3}$ Giménez Caballero, Ernesto: “La espiritualidad española y alemana”, en La joven Europa, Berlín, 1942. Los arios rubios han necesitado siempre en sus empresas el complemento moreno. El ario inglés -representante del espíritu de «libertad» necesitó de un pueblo moreno que coincidiese con esa idea de destrucción del continente. Y la encontró en el pueblo judío. (No en vano fue un judío -Disraeli- quien fundara el imperio inglés).
} 
Espinosa y de algunas magnas personalidades de conversos hispanos... (Sánchez Albornoz, 1973, p. 164).

Como hemos visto, las opiniones de Sánchez Albornoz son oscilantes, pero no podemos decir que sean racistas, aunque hay cierta contundencia en algunos juicios, como el que se fundamenta en Renán y, por qué no decirlo, alguna dosis de prejuicio, como la que surge de la discusión acerca del origen judío de Vives, que él cuestiona. Su duda proviene de su aspecto y, sobre todo, que siguiendo a Renán considere que los judíos de España no eran españoles. Es por ello que nos entristece que un historiador de su fuste, máxime cuando su pensamiento fue el que transcribimos, funde su opinión en la de este polígrafo francés, porque no lo prestigia. En efecto, Renán es mencionado junto Gobineau como forjador del mito ariano y su obra está conceptuada como un clásico del antisemitismo. Esta opinión es sostenida por Poliakov, que nos dice que su enfoque antijudío es racista. Traverso lo cita, de igual manera: "La raza semítica se reconoce casi únicamente por caracteres negativos..." (Traverso, 2003, p. 223). Una publicación refiere que la obra que contiene su opinión es uno de los best sellers antisemíticos ${ }^{4}$. Es más, Pérez releva a Gobineau de ser antisemita, aunque sí racista, pero su opinión respecto de Renán corrobora las anteriores, dado que, según él, tiene el convencimiento de que los semitas son inferiores a los arios (Pérez, 2005, p. 84).

Nos parece oportuno citar algunas reflexiones algo irónicas de Caro Baroja que parecieran dirigidas a Sánchez Albornoz, por ser éste castellano:

Los castellanos o los españoles de lengua castellana, que se han erigido con frecuencia en repartidores de atributos, cualidades y defectos, han solido decir que vascos y catalanes tienen algo de rasgos judaicos. Esto si se funda en que han observado la

\footnotetext{
4 "Nietzche y la cultura judía”, corregida por Jacob Golomb Routledge, Londres y Nueva York, 1997.
} 
tendencia a la especulación que existe desde antiguo en Vasconia y Cataluña. Y dada su incapacidad para llevar sus negocios bien ordenados, con cierta perseverancia, no han buscado más allá para establecer cierta similitud (Caro Baroja, 1978, pp.294-296).

Luego pareciera refutar aquello de la diferenciación entre españoles y judíos:

A nadie se le ha ocurrido pensar, en cambio, que en el carácter que se tiene por castellano clásico puede haber algo de judaico... Y es el que tanto castellanos como judíos, en su intervención en la vida pública, han partido de una concepción del mundo muy parecida, cuando han ejercido fuerte influencia en la Historia... El español, como el judío, en una época es atormentado, irónico, orgulloso, unitario, deseoso de autoridad, poco dado a ensueños y al goce la naturaleza” (Caro Baroja, pp.294-296.)

No queremos pensar que como uno es vasco y el otro castellano, como casi siempre ha ocurrido en la historia, se "tiren" con sus judíos para agraviarse.

Según se vio, los argumentos de Sánchez Albornoz son de orden étnico y cultural.

Se impone entonces revisar la historiografía de la historia de España en la materia.

En primer lugar corresponde señalar la opinión contundente de Domínguez Ortiz respaldada por estudios antropológicos efectuados en restos de la necrópolis de Montjuich, por los cuales se determinó que los hebreos de la época medieval diferían muy poco de los actuales españoles (Domínguez Ortiz, p. 142). 
En el mismo sentido Carrete Parrondo señala que conviene desechar cual connotación de carácter étnico en relación al concepto de judío y que es un término absolutamente cultural (Carrete Parrondo, 2000, p. 14).

A su vez la antropóloga Stallaert corroborando esa interpretación remite a varios autores para sustentarla. Entre ellos a Joseph Pérez, quien como vimos al comienzo basándose en García Iglesias, implícitamente niega diferencias étnicas, en otras de sus obras lo explicita de la siguiente manera: "En la España medieval los judíos no eran una raza, ni una casa, ni una clase social. Formaban una microsociedad junto a la sociedad cristiana mayoritaria." Tampoco - según esa autora - no formaban un grupo homogéneo que tenía a sus ricos y sus pobres e incluía a todos los oficios, desde la agricultura hasta las altas finanzas.

La antropóloga agrega que quien aborda el aspecto cultural, además del étnico es Ladero Quesada, que sostiene "los judíos, a decir verdad, no tenían una cultura propia, salvo en lo que derivaba directamente de la religión de los cristianos era su religión y las costumbres que derivaban de la misma, y que no eran una raza"

Suárez Fernández que además de ser académico de la historia, fue monárquico y acusado de pertenecer a la derecha por haber ocupado cargos durante el gobierno de Franco, o sea insospechado de exagerar una defensa de los judíos, sin embargo enfáticamente opina que: "Los judíos fueron en España, una minoría religiosa, no étnica” (Suárez, 2003, p. 14).

Las opiniones que preceden demuestra que una abrumadora mayoría de historiadores coinciden en no distinguir a judíos de españoles y para corroborar esa afirmación quizá debamos citar también la del agudo observador de los judeoconversos que es el profesor Márquez Villanueva que prologó la obra de Domínguez Ortiz señaló: “El converso, sin embargo, no era reconocible por ningún rasgo ni estigma biológico, sino por un consenso socioambiental que, por lo común, no se materializaba más que en momentos y casos excepcionales" (Domínguez Ortiz, 1991, p. 13). 
Como se podrá comprobar con los juicios emitidos por tan eminentes historiadores, la opinión de Sánchez Albornoz resulta prácticamente aislada. Si a ello se agregan los argumentos que veremos más adelante relacionados con el filosefardismo, ese aislamiento se acentúa aún más.

No obstante nos preguntamos qué hubiera ocurrido si Sánchez Albornoz estuviera vivo y se hubiera enterado de la decisión del gobierno español. ¿Hubiera ardido de indignación? Pensamos que no, porque en otras de sus contradicciones en la temática, la españolidad ("rasgos de españolía") que le negaba a los judíos que vivieron en España se la reconocía a los sefarditas por el mundo (Sánchez Albornoz, p. 176).

b) El otro aspecto a considerar es el que se relaciona con la España de los siglos XIX XX, a la que podemos llamar posinquisitorial, y se caracteriza porque esta nación ya no tenía judíos. Esto hace que el ofrecimiento de España que estamos considerando merezca, además, otras consideraciones históricas para su comprensión.

Son conocidos como sefarditas los judíos de España que fueron expulsados de ese reino en 1492 porque se negaron a la conversión religiosa, mientras que los que la consintieron pudieron permanecer. Éstos, unidos a las conversiones masivas realizadas con anterioridad, constituyeron una parte muy importante de la población española que con el transcurso del tiempo se asimiló totalmente -con exclusión de los Chuetas de Mallorca-, lo que hizo decir a un calificado franquista como Astrana Marín "de tantos judíos como hay, no sabe ya quién lo es ni quién no lo es" (Álvarez Chillida, 2002, p. 270).

Esa situación hace que aunque no haya habido judíos, la presencia judía en España no pueda ser considerada sin la que corresponde a los judeoconversos, lo que también fue motivo de disputa entre Américo Castro, que les otorga enorme importancia en el papel que 
jugaron, mientras que Sánchez Albornoz eleva otra vez su queja, por lo que entiende como exageraciones en las que incurre su contendiente.

Quien alude a ese aspecto la controversia es Márquez Villanueva dimensionando históricamente el diferendo sosteniendo:

(...) Quienes se muestran escépticos de que todo se resuelva por la llave maestra de los conversos (cosa que ni Castro ni nadie afirma) son los mismos que nos le conceden ninguna atención. Por encima de de muy diversas tendencias, nos hay especialista en el campo (sea cual sea su escuela o ideología) que no se halle persuadido de su decisiva importancia para una intelección profunda del pasado español...” (Domínguez Ortiz, 1991, p. 16).

Eso queda demostrado cuando se analiza la genealogía de algunas personalidades españolas. En los siglos XV y XVI, por ser más cercanos a la fecha de la conversión, podía determinarse la descendencia de las personas y de esta manera se sabe que algunas de ellas que trascendieron en lo religioso y la literatura, como son los casos de Santa Teresa de Jesús, Fray Luis de León y Fernando de Rojas, tenían ese origen. Los expulsos se dirigieron a distintos países, y su amor por Sefarad (España) hizo que conservaran el idioma y las costumbres, y que nunca renunciaran a sentirse españoles. Lo que ahora se presenta como novedosa medida registra algunos antecedentes.

También corresponde destacar que la cuestión no resulta absolutamente novedosa dado que hubo sefarditas nacionalizados como españoles, lo que tuvo vital importancia para que ellos pudieran ser salvados del exterminio nazi y por lo tanto corresponde analizar brevemente los antecedentes históricos en la materia. En el caso de los asentados en el imperio 
otomano, tuvieron el status de "protegidos", encuadre que surgía de los tratados internacionales entre el imperio Otomano y los Estados cristianos europeos. Se denominaban "capitulaciones" y consistían en la concesión de privilegios a los cristianos residentes en el imperio. Entre ellos, el más importante era el que no respondían ante la jurisdicción otomana, sino ante las de sus consulados, lo que permitió que también se pudieran acoger a ese régimen los sefardíes. Basado en esto, España otorgó la ciudadanía completa a esos protegidos mediante un decreto que promulgó en 1924 Miguel Primo de Rivera. Aquel texto ofrecía a los "protegidos" la posibilidad de adquirir la ciudadanía española hasta el 31 de diciembre de 1930, pero los que estuvieron en condiciones de acogerse fue una pequeña minoría basado en esa condición geográfica y de allí la importancia de la medida actual.

Ahora bien, después de las consideraciones precedentes sobre la presencia judía ¿qué ocurrió, además, en el transcurso de tantos siglos sin la misma para que este ofrecimiento fuera posible? España, al decir de un hispanista como Joseph Pérez, no solamente era una nación sin judíos, sino que se había olvidado de ellos. Los "redescubrió" en las campañas militares españolas en el norte del África y la sorpresa fue mayúscula. De ese modo, se enteró España de que al otro lado del Estrecho de Gibraltar, vivían miles de sefardíes. Al respecto, en julio de 1887 y bajo el título "Impresiones de Marruecos. Los Judíos" se publicó en el diario El Liberal lo siguiente: "Si se observan fisonomías es necesario remontarse al recuerdo de aquellos semblantes ¡cuántas caras españolas entre los judíos de Tetuán! ¡Cuántas caras judías entre los españoles...” (Stallaert, 2006, p. 253). A partir de ese momento se creó una corriente de simpatía hacia los sefarditas denominada sefardofilia y se inició una campaña filosemita que se corporizó en Emilio Castelar quien presidió el gobierno en 1881 y en Ángel Pulido que fue un médico y senador vitalicio que viajó en 1903 por los países del Danubio en el que tomó contacto con las comunidades de ese origen y también quedó profundamente impresionado que hizo que iniciara una campaña de 
acercamiento y escribió artículos sobre esa inquietud y un libro que se llamó "Españoles sin patria".

Como resultado de esta tendencia, se crearon institutos de estudios que no se limitaron a los sectores liberales; también abarcaron a sectores más tradicionales cuyos representantes más genuinos y eminentes fueron Menéndez y Pelayo y la escuela de Ramón Menéndez Pidal, quien vio en aquella producción conservada por la tradición oral entre los sefardíes de Marruecos una confirmación de sus tesis sobre el viejo romancero medieval.

En suma, se interesaron por la cultura sefardí como testimonio vivo de su españolidad.

También hubo un filosefardismo político de derechas del que participaron activamente intelectuales como Giménez Caballero y Foxá, que luego confluirán en el falangismo.

Nada menos que Francisco Franco participará de esa corriente, y cuando oficialmente se cree en 1941 el Consejo Superior de Investigaciones Científicas también se pone en marcha la Escuela de Estudios Hebraicos, que pronto comenzará a editar la revista Sefarad. En 1942, con el Eje en el apogeo de su poder, Franco insertará en un guión cinematográfico que había escrito y al que denominara "Raza" a un protagonista principal, que sería él mismo, y que actuará como guía a su madre por las calles de Toledo. En ese recorrido, y frente a la Iglesia Santa María la Blanca -que antes había sido sinagoga-, le cuenta que los judíos se habían purificado al contacto con España y que los judíos de Toledo se habían opuesto a la crucifixión cuando fueron consultados por los fariseos. Para él, la superioridad de la Nación española se manifestaba por su capacidad de purificar hasta a los judíos, convirtiéndolos en sefardíes, bien diferentes de sus correligionarios ashkenazíes. 
Ya desde sus años en la guerra de Marruecos, recuerda el apoyo judío a los españoles. Y en 1926 publicará en la Revista de tropas coloniales un artículo titulado "Xauen la triste”, en el que resaltaba la gran dignidad y las virtudes de los hebreos que acompañaron a los españoles en su retirada de la ciudad rifeña a finales de 1924. Desde aquellos años africanos, Franco habría de mantener amistad con varios notables judíos de aquel territorio, algunos de los cuales lo ayudarán activamente en la sublevación de julio de 1936.

Por esas razones, el antisemitismo español presentará ciertas singularidades que no fueron comunes a las otras naciones europeas, y que movieron a Stanley Payne a hablar de la “Paradoja española: el prejuicio tradicional y sefardofilia” (Payne, 2008, p. 323).

El mencionado Astrada Marín expresa mejor esa paradoja al declarar: "Yo, aunque antisemita sin rebozo... dejo aparte a los verdaderos sefardíes, porque antes que antisemita soy español... Ése ya no es el judío que yo combato... Ese judío no es propiamente judío" (Álvarez Chillida, 2002, p. 270). También resulta paradójico que algunos sefarditas hayan apoyado al bando nacional en la guerra civil cuando el mismo era aliado de la Alemania nazi.

En conclusión, el ofrecimiento de ciudadanía está en línea con aquellos hechos ya lejanos y es la consecuencia histórico legal del decreto de 1969 que derogó el Edicto de Granada por el cual se expulsó a los judíos España. 


\section{Bibliografía}

Álvarez Chillida, G (2002). El Antisemitismo en España: la imagen del judío 1812-2002. Madrid: Marcial Pons Ediciones de historia.

Armstrong, K. (1995). Una historia de Dios. 4000 años de búsqueda en el judaísmo, el cristianismo y el islam. Buenos Aires: Editorial Paidós.

Avruj, A. (2005). Consecuencias del antisemitismo. Publicado el 19 marzo 2005, de http://edant.clarin.com/suplementos/cultura/2005/03/19/u-941294.htm

Baer, Y. (1959). Historia de los Judíos en la España Cristiana, Madrid: Ed. Altalena.

Bennasar, B. (1996). Franco. Madrid: Edaf.

Cantera Montenegro, E. (1998). La Imagen del Judío en la España Medieval. Espacio, Tiempo y Forma. Revista de la Facultad de Geografía e Historia, pp. 11-38. (Madrid: Universidad Nacional de Educación a Distancia).

Caro Baroja, J. (1978). Los Judíos en la España Moderna y Contemporánea. Madrid: Ed. ISTMO.

Carrete Parrondo, C. y Pérez J. M. (2000). Los judíos en la España contemporánea: historia y visiones, 1898-1998, T VIII. Madrid: Universidad Castilla La Mancha.

Castro, A. (1971). La Realidad Histórica de España. México: Porrúa.

Domínguez Ortiz, A. (1991). La Clase Social de los Conversos en Castilla en la Edad Moderna. Granada: Ed. Universidad de Granada. 
Dujovne Ortiz, A. (2005). Campeonato de sufrimientos. Diario La Nación. Publicado el 22 de abril de 2005.

Dujovne, L. (1949). Introducción a la historia de la filosofía judía. Buenos Aires: Ed. Israel.

Fonti, D. (2005). Morir en la era de la técnica. EDUCC, Universidad Católica de Córdoba: Córdoba.

García Cárcel, R. (1998). La Leyenda Negra. Historia y Opinión. Madrid: Alianza.

Gitlitz, D. M. (2003). Secreto y Engaño. La religión de los Criptojudíos. Madrid: Ed. Junta de Castilla y León.

González, I. (2009). Los Judíos y la Guerra Civil Española. Madrid: Hebraica ediciones.

Hering Torres, M, (2011). Limpieza de Sangre, ¿Racismo en la Edad Moderna?. Institüt für Geschichte (Universität Wien) (PDF en internet)

Kamen, H. (1967). La Inquisición Española. Barcelona: Ed. Grijalbo. Kamen, H. (2007). Los Desheredados. España y las huellas del exilio. Madrid: Aguilar.

Kuznitzky, A. (2014). España, el Antisemitismo y el Holocausto. De la Inquisición a Franco y los nazis. Buenos Aires: Ed. Distal Libros.

Kuznitzky, A. (2006). La leyenda negra de España y los marranos. Toledo 1449Núremberg 1935, ¿hacia otra leyenda negra? Córdoba: El Emporio ediciones. 
Lacave, J. (1992). El judaísmo español en la época de los Reyes Católicos. En Cinco siglos de presencia judía en América. Buenos Aires: Editorial Sefarad.

Levinas, E. (2004). Difícil libertad. Madrid: Caparrós editores.

Muntaner Mariano, L1. (2008). Breve historia de los Chuetas, antijudaísmo y antisemitismo en la Isla de Mallorca como presentación del libro Raíces Chuetas, alas judías. Palma de Mallorca: Ed. Lleonard Muntaner.

Netanyahu, B. (1999). Los Orígenes de la inquisición. Barcelona: Crítica.

Netanyahu, B. (2005). De la anarquía a la Inquisición. Estudio sobre los conversos en España durante la baja edad media. Madrid: Ed. La esfera de los libros.

Payne, S. (2008). Franco y Hitler. España, Alemania, la Segunda Guerra Mundial y el Holocausto. Madrid: Ed. La Esfera de los Libros.

Pérez, J. (2005). Los Judíos en España Madrid: Marcial Pons.

Preston, P. (1994). Franco caudillo de España. Barcelona: Ed. Grijalbo Montalvo.

Rother, B. (2005). Franco y el Holocausto. Madrid: Ed. Marcial Pons.

Salazar Acha, J. (1991). La limpieza de sangre. Conferencia pronunciada en el Instituto de Historia de la Inquisición y publicada en Revista de la Inquisición.

Sánchez Albornoz, C. (1973). España, Un Enigma Histórico. Barcelona: Ed. Hispano América. 
Stallaert, C. (2006). Ni una gota de sangre impura. Barcelona: Galaxia Gutenberg.

Sicroff, A. (1985). Los Estatutos de Limpieza de Sangre. España: TaurusStallaert, C. (2006). Ni una gota de sangre impura. Barcelona: Editorial: Galaxia Gutenberg.

Suárez Fernández, L. (2002). Las ciudades castellanas y el problema judío. Judaísmo hispano. En Estudios en memoria de José Luis Lacave Riaño; Junta de Castilla y León, Diputación Provincial de Burgos, Consejo Superior de Investigaciones Científicas; pp. 689698; Madrid.

Suárez, L. (2003). Los Judíos. Barcelona: Ariel.

Traverso, E. (2003).La violencia nazi: una genealogía europea. Buenos Aires:Fondo de Cultura Económica.

Todorov, T. (2009). Nosotros y los otros: reflexión sobre la diversidad humana. Buenos Aires: Siglo XXI Ediciones.

Vives, V. (1978). Aproximación a la historia de España, T. III. Barcelona: Edit. VicensVives. 